\title{
Correspondências artísticas e níveis de representação: direção de arte em $L$ ' Inhumaine (Marcel L' Herbier, 1923)
}

\section{Tainá Xavier}

Programa de Pós Graduação em Artes Visuais - Universidade Federal dório de Janeiro. Mestranda Linha de Pesquisa: Imagem e Cultura. Orientador: Prof. Dr. Rogério Medeiros

Diretora de arte, formada em Cinema pela Universidade Federal Fluminense, recentemente foi responsável pela direção de arte do longa-metragem Noites de Reis, de Vinícus Reis, El Desierto Produções.

Resumo: A presente pesquisa propôs-se a analisar o campo criativo da direção de arte de cinema e suas relações de significação com a linguagem cinematográfica, através do estudo de caso do filme L' Inhumaine (Marcel L' Herbier, 1923). Partiu-se da inserção do cinema no conjunto das manifestações culturais modernas, que lidam com os limites entre realidade e representação, buscando-se nos elementos prófilmicos a compreensão da construção dos códigos regentes da visualidade criada pela direção de arte. Para tal, utilizou-se como referencial teórico o pensamento de Ismail Xavier, Marc Vernet, Chistian Metz, entre outros, e abordou-se o período de institucionalização do cinema industrial, sendo de especial importância estudos sobre o cinema dos pioneiros e as vanguardas artísticas europeias dos anos 1920.

Palavras-chave: cenografia, cinema, figurino, modernidade

Title: Artistic correspondences and levels of representation: art direction in L' Inhumaine (Marcel L' Herbier, 1923)

Abstract: The present research proposes to analyze the creative field of film art direction and its relationship of signification with cinematic language, through the case study of the film L'Inhumaine (Marcel L' Herbier, 1923). We started from the insertion of cinema in modern cultural events, which deal with the boundaries between reality and representation; we seek in the pro-filmic elements the understanding of the building codes that rule of the visuality created by art direction. As theoretical reference, we used the writing of Ismail Xavier, Marc Vernet, Chistian Metz, among others, and we decided to approach the period of institutionalization of the film industry, being particularly important the film studies of the pioneers and the 1920's European artistic avant-gardes. Keywords: cinema, costume, set decoration, modernity 
Título: Correspondencias artísticas e niveles de representación: dirección de arte en L' Inhumaine (Marcel L' Herbier, 1923)

Resumen: Este estudio tuvo como objetivo analizar el campo creativo de la dirección de arte en cine y la importancia de su relación con el lenguaje cinematográfico, a través del estudio de caso de la película L'Inhumaine (Marcel L'Herbier, 1923). Partimos de la inserción de la película que se desarrolla en el conjunto de las modernas manifestaciones culturales, que se ocupan de los límites entre realidad y representación, se buscando en los elementos pro-fílicos la comprensión de los códigos de construcción que rigen el visual creado por la dirección de arte. Con este fin, hemos utilizado los escritos teóricos de Ismail Xavier, Marc Vernet, Chistian Metz, entre otros y enfocamos el período de institucionalización de la industria del cine, siendo especialmente importantes los estudios de la producción de los pioneros y el arte de las vanguardias europeas de los años 1920.

Palabras-clave: cine, escenografía, modernidad, traje

Concebido para expressar as tendências da arte moderna francesa da época e ser apresentado na Exposition des Arts Décoratifs et Industrielles Modernes realizada em Paris, em abril de 1925, o filme L' Inhumaine dirigido por Marcel L' Herbier e produzido em 1923, apresenta objetos, cenários e figurinos no estilo art déco criados por artistas de destacada atuação no cinema, nas artes plásticas, arquitetura, decoração e moda. As pesquisas estéticas apresentadas nesse filme resultam em importantes contribuições para a representação do espaço cênico cinematográfico, em um contexto de consolidação da direção de arte como campo autônomo de criação.

Por ocasião do lançamento da cópia restaurada de L' Inhumaine, no Festival de Outono em Paris, o jornalista Jacques Sicilier afirma a importância da obra, por tanto tempo esquecida:

Em retorno dos Estados Unidos, a cantora Georgette Leblanc diz ao diretor Marcel L' Herbier que um financiador nova-iorquino se interessaria por um filme que mostrasse as tendências atuais da arte francesa, do qual ela fosse a vedete. Assim nasceu L'Inhumaine, história fantástica imaginada por Marcel L' Herbier para Georgette Leblanc, adaptada por Pierre Marc Orlan. Para fazer cinematograficamente a síntese das artes decorativas do momento, L' Herbier confia os cenários ao pintor cubista Fenand Léger, ao arquiteto Robert Mallet-Stevens, a Claude Autant-Lara e a Alberto Cavalcanti. Os móveis são projetados por Pierre Chareau, os figurinos pelo costureiro Paul Poiré. Darius Milhaud escreveu a música de acompanhamento para orquestra. [...] A intriga é pretexto ao modernismo da composição, do ritmo, da montagem das imagens e de um manifesto art déco. A obra, uma das mais significativas e mais importantes do cinema francês dos anos 1920, não obteve sucesso nesta época. Só foi redescoberta mais tarde. (SICLIER, 1986) 
Em linhas gerais, L' Inhumaine narra os conturbados dias de Claire Lescot (interpretada por Georgette Leblanc), uma famosa cantora, após sua decisão de sair pelo mundo ao fim de uma temporada em Paris. Durante luxuosa e excêntrica recepção que oferece em sua casa, a artista recebe uma série de propostas para abandonar seu intento, vindas dos diversos admiradores que a cercam e finda por aceitar a corte do marajá Djorah de Mopur (Philippe Hériat). No entanto, é o engenheiro Einar Norsen (Jaque-Catelain), que chegara atrasado à festa, quem parece realmente amá-la. A “rica, emancipada e inacessível a ambições ordinárias" i Claire Lescot despreza Einar, que sai da festa sai da festa desolado. No caminho, seu carro cai de um precipício e afunda no rio. Culpada pela suposta morte do engenheiro a cantora tem seu habitual comportamento "desumano" profundamente abalado. Após sua última apresentação um personagem misterioso surge dizendo querer falar sobre Norsen. Ele diz que o corpo do engenheiro foi encontrado e que Claire deve ir a seu laboratório para fazer o reconhecimento. Levada ao laboratório pelo misterioso personagem, Claire depara-se com um corpo coberto por um lençol branco. Vê-se, então, Einar descer as escadas para encontrá-la. Após revelar que era ele o personagem misterioso, o engenheiro mostra à Claire sua mais nova invenção, a qual a fará desistir de viajar: o STF, um sistema capaz de enviar o som da música de Claire para o mundo, bastando que a artista cante em um microfone. A aparelhagem também permite que sejam vistas, em uma grande tela, as imagens das pessoas ouvindo o som transmitido da voz de Claire. Einar também fala de outra invenção sua: uma máquina capaz de reanimar o coração. Ao sair do laboratório para mais uma apresentação no teatro, Claire é surpreendida pelo enciumado marajá, que lhe prepara uma armadilha fatal: um grande buquê de flores (com um falso cartão de Einar), contendo uma serpente venenosa. Disfarçado de motorista, Djorah conduz o carro da cantora, negando socorro quando Claire, no interior do veículo, recebe a picada mortal. O marajá entrega para o engenheiro o corpo inanimado de sua amada. Einar rapidamente leva o corpo de Claire para o laboratório onde, após duas tentativas frustradas, consegue reanimá-la e, enfim, os dois se olham apaixonados.

Com base em uma divisão metodológica da imagem cinematográfica em níveis de representação, obtida a partir da abordagem das formas de representação do real pelo cinema por Marc Vernet, aborda-se os componentes da direção de arte de L' Inhumaine, dispostos no espaço cênico para definição, por meios visuais, da materialidade dramática das personagens. Ao afirmar que "qualquer filme é um filme de ficção" (AUMONT et al, 2007, p. 100) Vernet aponta para o fato de o cinema operar diferentemente do teatro, em que o que é representado é fictício, ao passo que o que representa (atores, cenários etc.) é real. No cinema (mesmo o documental), essa instância é 
sempre fictícia, ou seja, o modo como a história é contada resulta sempre de uma narrativa composta de objetos, personagens, espaços que não estão fisicamente presentes na sala de espetáculo.

No caso do cinema de ficção propriamente dito, também denominado narrativo, percebe-se uma dupla instância de representação, sendo a primeira composta pela encenação fictícia do roteiro, feita com atores reais, em cenários reais, representando um enredo fictício. Essa primeira instância (similar ao tipo de representação operada no teatro), contudo, ainda não se constitui em espetáculo; ela será registrada por uma câmera, o que resultará em uma segunda instância narrativa de representação. A ambientação cênica, assim como os atores, seu vestuário e sua caracterização são elementos pró-filmicos, ou seja, são "dotados de uma existência e uma significação preexistente à tomada cinematográfica" (COSTA, 2003, p. 229).

Ismail Xavier destaca as continuidades que o cinema narrativo traz do teatro naturalista no tocante à mise-en-scéne, que o inscrevem em uma tradição bem definida de espetáculo, que confere à representação um espaço próprio, seguindo os postulados do drama sério burguês que Diderot elaborou no século XVIII. O cerne dessa semelhança aponta para a oposição cena/espectador, conforme destaca o artigo de Barthes, "Diderot, Brecht e Einsenstein”, citado pelo autor. "Tal fronteira emoldura o espetáculo, funciona como uma janela que se abre para o mundo imaginário da cena que se desenrola suspensa em uma plataforma, à disposição do olhar do espectador que, embora cheio de empatia, permanece ciente do 'hiato' que os separa.” (XAVIER, 1996, p. 249)

Embora a separação intransponível do espaço da representação e da observação no espetáculo cinematográfico decorra do teatro naturalista, o fato de a narrativa do filme ser mediada pelo registro da câmera, que exclui a presença física do representante, amplia a oposição cena/espectador, conforme afirma Christian Metz:

[...] a cenografia [de teatro], por exemplo, não tem o efeito de criar um universo diegético, não passa de uma convenção dentro do próprio mundo real. (Poderíamos acrescentar, na mesma perspectiva, que a assim chamada 'ficção' no cinema é a diegese, enquanto no teatro a 'ficção' só existe como 'convenção' [...].) O espetáculo cinematográfico, pelo contrário, é completamente irreal, ele se desenvolve num outro mundo [...]: o espaço da diegese e o da sala (que envolve o espectador) são incomensuráveis, nenhum dos dois inclui nem influencia o outro, as coisas ocorrem como se houvesse uma parede invisível, porém intransponível. (METZ, 1972, p. 26)

Ao mesmo tempo em que só mostra os registros, em vez de os objetos físicos da representação, e apesar de sua condição construída, a percepção de realidade no cinema atinge altos 
índices de aceitação pelo espectador. Esse processo, porém, tem pressupostos a serem rigidamente seguidos para que não haja qualquer conflito que perturbe sua percepção. Esses pressupostos exigem a ocultação do caráter de construção da imagem cinematográfica, através dos códigos estabelecidos na linguagem clássica narrativa do cinema e do veto em permitir a revelação pela imagem visível na tela, do aparato técnico dos meios de produção dessa imagem e dessa "realidade" construída.

A época de surgimento de L'Inhumaine constitui um período de construção dos pressupostos narrativos do campo de criação da direção de arte que ocorre em consonância com pesquisas de busca do código de representação específico do cinema e da conformação do sujeito e do espaço modernos. Ao entender o filme como parte integrante desses processos, busca-se perceber até que ponto os resultados expressivos empregados na direção de arte se alinham (ou não) às proposições que se tornaram dominantes na constituição do cinema clássico narrativo. Para tal, são analisados, primeiramente em separado, os universos visuais das personagens protagonistas para, em seguida, articulá-los à visualidade pró-fílmica geral de L'Inhumaine e à sua estrutura enunciativa.

O primeiro cenário apresentado, a villa ${ }^{\text {ii }}$ (vivenda) de Claire Lescot, cuja criação da fachada coube ao arquiteto Robert Mallet-Stevens, ocupa posição central na narrativa. Majestosamente situada no topo de uma colina, com vista para a cidade de Paris, ergue-se a grande construção em linhas retas: composição assimétrica de cubos e paralelepípedos de concreto sobrepostos e recortados por janelas, as quais são grandes planos envidraçados. É noite e o entorno escuro e vazio evidencia a conformação volumétrica da construção pelas áreas de luz e sombra, reforçada pela mudança do enquadramento frontal para o diagonal. A grande porta que dá acesso ao interior da construção, adornada por formas geométricas retilíneas e circulares, vazadas em uma superfície escura de forma a permitir forte contraste com a luz que emana do interior, situa-se na área central da construção, em um patamar elevado em relação ao solo ao qual um lance de escadas dá acesso. Ponto de convergência do olhar, esse elemento de transição dos domínios público e privado conduz ao interior da residência. O primeiro plano a enfocar o cenário do interior apresenta como únicos elementos de ligação com o espaço exterior os mesmos serviçais já vistos anteriormente. Os elementos arquitetônicos de base não seguem conformação visual homogênea com a da fachada, ocasionando uma ruptura da continuidade presumida entre os dois segmentos dessa mesma construção. Portais e janelas em arcos ou ângulos agudos usados nos espaços interiores, por 
exemplo, não correspondem às aberturas retangulares que se vê na fachada externa.
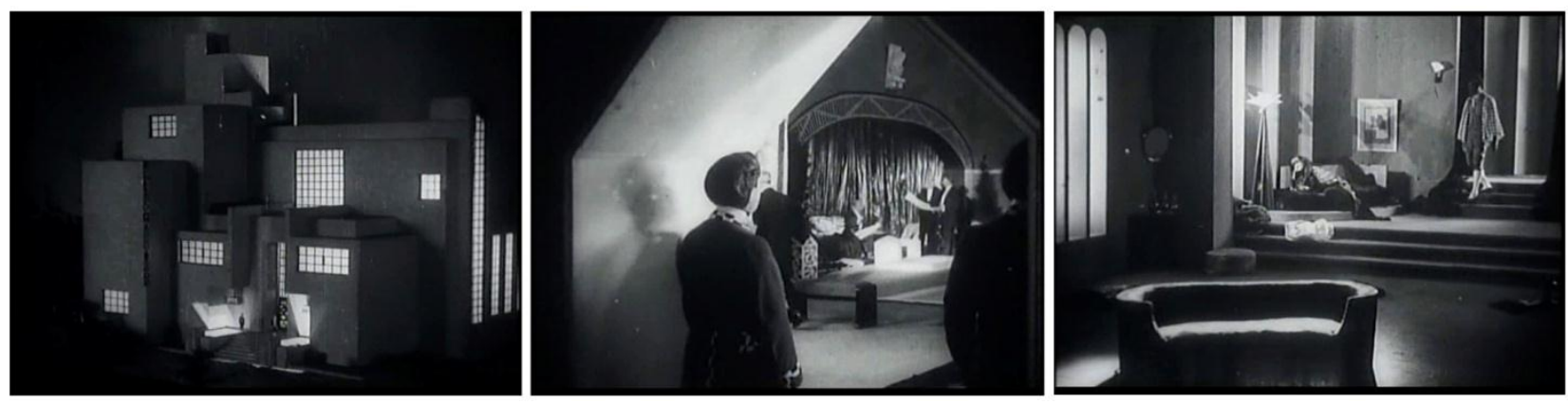

Il. 1. Comparativo de conformação geométrica dos elementos arquitetônicos exteriores e interiores na Villa Lescot.

Excertos de L'Inhumaine. DVD lançado por ocasião do Le $2^{\circ}$ Printemps des Ciné Concerts Bordeaux.

Cenário eclético e teatral, o salão de festas representa o universo de aparências em que vive "a desumana". Criado por Alberto Cavalcanti, o cenário compõe-se de um patamar retangular central com piso revestido por uma padronagem geométrica preta e branca. Todo cercado de água, parece querer indicar sua inacessibilidade. Sobre a superfície desse patamar situa-se uma enorme mesa de jantar. Duas passarelas em diagonal sobre a água o ligam ao restante do salão. Duas escadarias se elevam para um plano acima do salão e uma diagonal ascendente é formada pelos vértices dos degraus em forma de secções de losangos. Claire surge na parte superior do quadro. Ela aparece no centro de uma imagem simétrica e seu posicionamento no enquadramento está alinhado verticalmente ao vértice do ângulo agudo do espaldar da cadeira onde se sentará para jantar. A cantora surge, toda de branco em um ambiente no qual todos vestem preto, através de um portal em arco ladeado por grandes cortinas que reforçam a teatralidade de sua aparição.

Elemento inaugural de individualização da personagem de Claire, a Villa Lescot, em sua composição formal, agrega diversos valores ao estilo de vida da personagem, acima de tudo moderno como o aspecto exterior da fachada. Com imponentes volumes geométricos, suas aberturas envidraçadas apresentam seu gosto pela exposição, assim como a emanação luminosa que se vê é intensa como o fascínio que Claire desperta. Mostrado antes da aparição da personagem, seu interior, o salão agrega qualidades de suntuosidade e exibicionismo à sua proprietária em razão de suas grandes proporções e da composição alegoricamente teatral. Com a aparição de Claire, percebe-se que L'Herbier faz uso da aliteração por meio dos componentes expressivos visuais, uma vez que cenografia e figurino atuam no intuito de repetir e intensificar os constituintes de subjetividade das personagens. 
Em sua primeira aparição, a personagem de Claire veste um longo vestido de ombro único, de tecido branco. O brilho que apresenta no registro fotográfico atua como índice de nobreza do material, cujo caimento faz parecer tratar-se de cetim ou lamê. Sua modelagem reta apresenta leve estreitamento abaixo dos joelhos, altura pela qual a abertura de uma fenda possibilita a extensão do tecido em uma cauda. Criado pelo costureiro francês Paul Poiret, responsável por todo o figurino do filme, esse vestido destaca Claire em meio aos convidados masculinos. Sua tonalidade clara, somada ao brilho do tecido, reveste a cantora de luz, a qual é prolongada para além de seu corpo pela cauda do vestido. (http://www.youtube.com/watch?v=AEuHIwlllV8\&feature=youtu.be)

Claire, como um cometa, deixa um rastro luminoso por onde passa. Um de seus ombros, revelado nu, é o componente que desperta a sensualidade de sua figura, pois, em contraste com o ombro coberto, remete à nudez do restante de seu corpo. Outros componentes acrescentam valores de feminilidade e excentricidade ao traje, como as plumagens negras que envolvem o quadril da personagem, compõem seu leque e adornam o turbante branco que Claire traz na cabeça. O turbante com plumas, apresentado à sociedade parisiense por Poiret ao adornar a cabeça de sua esposa na estreia do ballet Le Minaret, em 1913, tornara-se a marca do costureiro e a consolidação da influência oriental na moda.

A pesquisadora americana Jane Gaines afirma que a utilização da expressividade visual do figurino no cinema mudo atua no intuito de suprir as sutilezas emocionais não alcançadas pela narrativa. Em seus propósitos de tradução visual da personalidade, esse figurino apresenta apenas as informações mais básicas daquela personagem e, conotando apenas uma camada superficial, comunica por uma tipificação das personagens (GAINES, 1990, p. 187). "A arte da costura consiste precisamente em desenvolver a individualidade que há em cada mulher. $\mathrm{O}$ modelo deve ser utilizado apenas como meio de sugestão, não de sujeição. Deve haver tantos modelos quanto há mulheres.” (POIRET, 2009, p. 77) Essa declaração, contida na autobiografia do costureiro, apresenta sua percepção de que há relação objetiva de equivalência entre a ordem interna sentimental da mulher e a externa material, expressa pelo vestuário. Essa concepção de que a roupa é uma chave para a individualidade emerge na sociedade moderna e desenvolve-se com base na possibilidade de manejo e aperfeiçoamento da personalidade com as instituições de consumo cultural (GAINES, Op. cit. p. 184-185).

Ao escolher o costureiro Paul Poiret como figurinista, L'Herbier agrega à Claire a marca desse estilo, efetua em sua personagem a aplicação de um código visual preestabelecido, dentro do qual se inseriria um subcódigo específico para o filme. Elementos principais desse código anterior 
são o brilho dos tecidos, o movimento dos drapeados, a leveza das plumas, a geometrização formal da modelagem e das padronagens que, junto com o alongamento da silhueta feminina, representativos do estilo que consagrou a Maison de Poiret, agregavam valores de glamour, modernidade e libertação feminina às suas criações, considerados por L'Herbier apropriados à caracterização desejada para Claire. Na medida em que se constitui elemento estilístico autônomo, o código do estilo de Poiret destaca visualmente a personagem de Claire de forma excessiva, ultrapassando as motivações dramáticas representadas e, com isso, interferindo na homogeneidade dos componentes narrativos do filme.

No documentário L'Architecture d'Aujourd'hui (Pierre Chenal, 1930), com roteiro de Le Corbusier e Chenal, o conceito da arquitetura moderna é apresentado por um paralelo da modernidade com a máquina. A sequência inicial declara o movimento como tema principal da nova arquitetura ao estabelecer conexão implícita entre ela e duas das principais conquistas no campo do transporte. A tomada de um carro, seguida por um intertítulo que explica que se trata de “uma máquina para dirigir", é seguida por uma de um avião, “uma máquina para voar”, e, finalmente, de uma construção moderna, a Villa Savoye, projetada por Le Corbusier, "uma máquina para viver" (ALBRECHT, 2000, p. 14-15). Percebe-se, pela composição narrativa da personagem de Einar, a manifestação dessa ideologia na medida em que se encontra a máquina como elemento intermediador das relações de Einar com o mundo.

Se na sequência da festa o engenheiro assume posição de inferioridade perante Claire, isso se deve à ausência dessa intermediação. Adiante veremos, na apresentação do RTF (máquina de transmissão de sons e imagens) e na ressurreição, a presença do aparato técnico como fator positivo na relação interpessoal de Einar com Claire, efetivando a máquina como extensão de sua personalidade.

A fachada criada por Mallet-Stevens para o laboratório do engenheiro, embora se assemelhe à Villa Lescot por meio da utilização de linhas retas verticais e horizontais na definição de seus volumes, difere da construção anterior em relação aos elementos de ligação do espaço externo com o interno. Ao contrário das grandes janelas iluminadas da villa, o domínio íntimo do espaço de Einar se mostra muito pouco ao exterior. Duas aberturas são responsáveis pelo fornecimento de informação luminosa emanante do interior; a ausência de fontes de luz artificial na fachada soma-se a esse fato, gerando um entorno escuro que concede uma atmosfera de mistério à construção e, por conseguinte, ao que ocorre em seu interior. 
Concebido e executado por Fernand Léger, o cenário do interior do laboratório é um amplo salão onde elementos cinéticos em movimentação pendular distribuídos por diversos pontos do cenário associam-se à movimentação de Einar e seus ajudantes na criação de uma imagem dinâmica que concede à totalidade do espaço um paralelo com o funcionamento das máquinas. Elementos luminosos aparecem nesse cenário, cuja iluminação geral também é abundante. Formas geométricas retilíneas somam-se a anéis dentados, arcos, discos e espirais, em uma referência à engrenagem mecânica que remete diretamente às pinturas de Léger. A distribuição dos elementos cenográficos no salão evidencia a tridimensionalidade do espaço, mas a constituição planar desses elementos, em sua ausência volumétrica, parece evidenciar o caráter ilusório da representação de profundidade na imagem fílmica bidimensional. Representação espacial menos realista de todo o filme, o cenário de Léger é um grande quadro em movimento, um espaço abstrato visitado pelas personagens do filme, erigido em consonância visual com as obras do artista, em especial aquelas em que se dedica à idolatria da máquina.
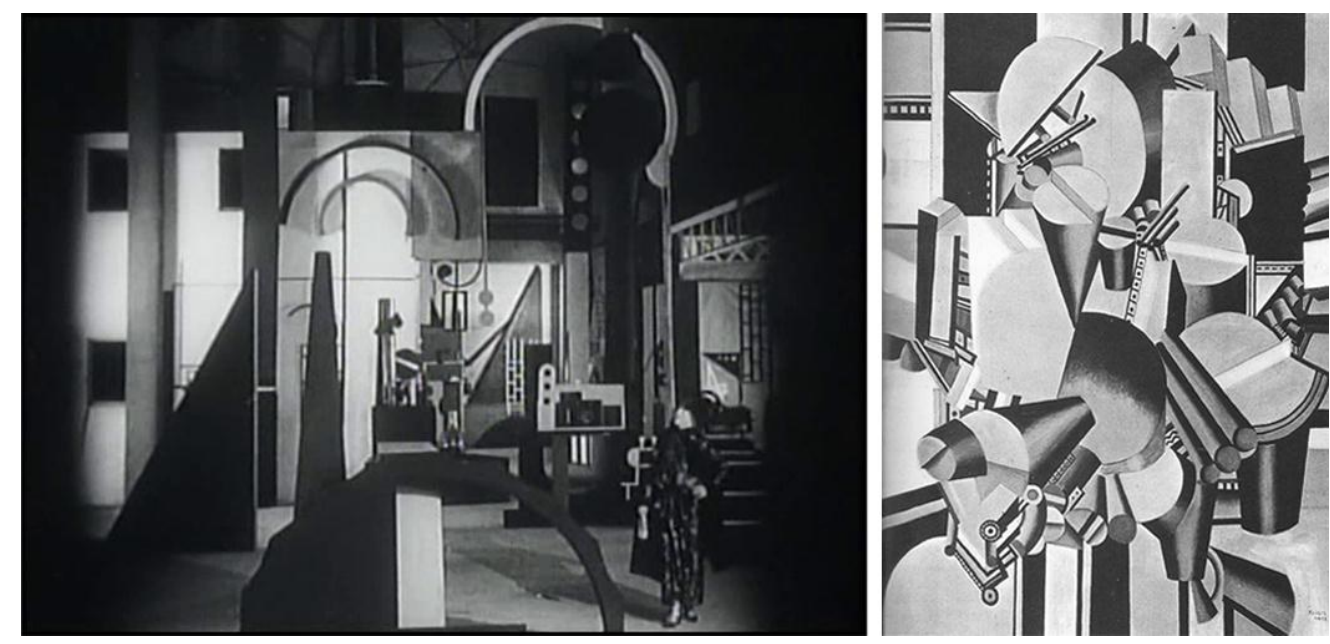

Il. 2. Interior do laboratório de Einar. Excerto de L' Inhumaine e quadro de Fernand Léger: Elementos mecânicos (1918 - 23),tela, 2,11 x 1,68 cm. ARGAN, 1992, p. 309.

Assim como a criação do figurino por Poiret, a execução desse cenário por Fernand Léger traz para o rico mosaico visual de L'Inhumaine um código preexistente, construído ao longo da pesquisa estética pessoal deste artista. Na medida em que a construção da diegese requer relação de continuidade dos espaços autônomos do exterior e do interior do laboratório, a confrontação desses dois códigos diferentes atua no intuito de negar esse pressuposto da construção narrativa fílmica.

No que concerne ao figurino, são os trajes empregados em momentos de operação de máquinas que apresentam mais explicitamente o elemento significante diferenciador de sua 
personagem: a configuração moderna da funcionalidade, que subordina a forma à função. Na primeira imagem que se vê de Einar, ele sai de seu laboratório e pula para o interior de seu carro sem capota vestindo um sobretudo preto de couro, uma touca e óculos característicos da prática do automobilismo. O primeiro plano a enquadrar o rosto de Einar mostra-o vestindo esse sobretudo, cujas golas levantadas em torno do pescoço evidenciam seu rosto e seus olhos, mimetizando-o em uma composição simétrica com os elementos geométricos da porta de entrada da Villa Lescot. (http://www.youtube.com/watch?v=j581RYsiz-w\&feature=youtu.be). Despido de seu traje funcional, Einar iguala-se aos demais no atendimento da norma vestimentar que rege a festa (casaca), sendo relegado a uma importância secundária por Claire. Nesse sentido, é interessante notar que a única personagem masculina que apresenta elementos individualizadores em seu traje (turbante) é o marajá Djorah, que sai da festa como o vencedor na corrida pela conquista de Claire.

Último figurino de Einar, o macacão branco da cena de ressurreição de Claire sobrepõe-se à roupa que o engenheiro usava ao aguardá-la, sendo vestido com base na necessidade de operação da máquina. Anteriormente apresentado em seus assistentes, e numa imagem mental de Einar por Claire, na cor preta, o macacão de trabalho no laboratório apresenta mangas longas, dois grandes bolsos externos, cintura marcada e é confeccionado em material brilhoso. A tonalidade branca do modelo usado por Einar destaca-o em meio a seus assistentes e ao entorno do cenário, que se torna escuro, em uma espécie de alusão ao desvio de toda potência elétrica do prédio para a máquina. Essa superfície clara também possibilita um bom registro das oscilações de iluminação e mudanças cromáticas que ocorrem na sequência de ressurreição de Claire.

A inexistência de tecidos sintéticos na época de realização do filme nos faz supor que o alto brilho que o material apresenta tenha sido acrescido em algum tratamento (pintura ou banho) sobre um tecido (ou couro) natural de base. O efeito visual desse material remete aos tecidos vinílicos e aos plásticos flexíveis que só seriam inventados mais tarde. É interessante notar que a associação funcional que se faz desse material com suas propriedades de isolamento da condução elétrica também seria uma característica dos plásticos. Disfarçado de sua origem natural, esse material integra o figurino ao cenário do laboratório, espaço composto exclusivamente pelos componentes não orgânicos da máquina. Nesse espaço não natural da tecnologia moderna, Claire é a única a revestir-se de materiais biologicamente criados. Em seu vestido de cetim e seu manteau, com aplicações de pele, o corpo inerte da "desumana" recobre-se dos únicos materiais orgânicos daquele espaço da técnica, que mobiliza toda sua energia no intuito de devolver-lhe a vida, envolvendo-a, 
portanto, em seu sistema. Ao receber a energia vital por meio da técnica, a personagem de Claire, anteriormente dissonante nessa ambiência, passa a fazer parte desse conjunto.

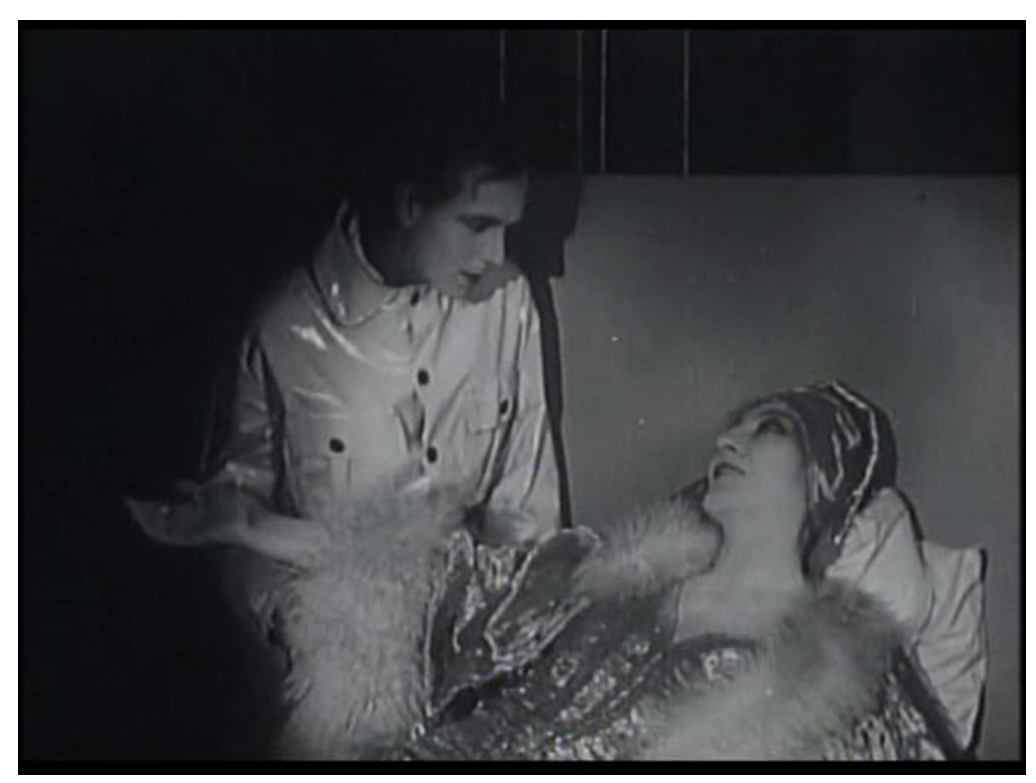

Il. 3. Figurinos finais de Einar e Claire. Excerto de L'Inhumaine.

Ao propor a exploração máxima das capacidades expressivas da linguagem visual no cinema, a posição vanguardista de L'Inhumaine ocupa importante papel, na medida em que efetua literalmente seu trabalho de deslocar-se à frente, preparando o terreno para o que se segue. Entre as operações estéticas apresentadas com pioneirismo na construção do espaço arquitetural ${ }^{\text {iii }}$ desse filme pode-se destacar uma série de proposições que se institucionalizaram no modelo do cinema industrial americano, como: a investigação do uso da iluminação artificial e do enquadramento como constituintes da representação do espaço cenográfico tridimensional; a utilização da estruturação do espaço cenográfico com bases nas técnicas da arquitetura em geral e na moderna, em particular como elemento de significação da vida moderna, e do cinema como veículo difusor dessa arquitetura e dos significados que se constroem a seu respeito; o estabelecimento de uma relação de mão dupla da alta costura com o cinema, em que a primeira agrega códigos visuais preestabelecidos às personagens e o segundo oferece as estrelas que propagam a influência da moda para além dos limites do filme. Essas, entre outras, vêm sendo reconhecidas na afirmação de L'Inhumaine como um dos filmes fundamentais que, somados a outras produções cinematográficas e demais pesquisas da visualidade e da representação, impulsionam as mudanças significativas da configuração física do espaço diegético no cinema. 
Com base nas considerações de Baudrillard sobre a configuração sistêmica do objeto e do espaço moderno, pode-se perceber que, em virtude de sua realização se dar em um período de constituição de uma nova estrutura, se encontra uma sobreposição de duas ordens de articulação dos objetos no espaço cenográfico de L'Inhumaine: uma forma abstrata e uma concreta, as quais se relacionam ao progresso objetivo do objeto técnico. Pelo paralelo da estrutura primitiva do motor do automóvel com a atual, o autor apresenta a passagem da forma abstrata, "na qual cada unidade teórica e material é tratada como um absoluto, necessitando, para seu funcionamento, constituir-se como sistema fechado", para a concreta, que "corresponde a um progresso objetivo do objeto técnico, uma vez que o problema tecnológico real reside na convergência de funções em uma unidade estrutural, e não em uma procura de compromisso entre as exigências em conflito" (BAUDRILLARD, 1973, p. 12). Regido pela lógica abstrata da autonomia entre as partes, o modelo de mosaico de estilos individuais para a construção da significação estética de L' Inhumaine baseiase na autonomia do objeto visual para a produção de sentidos absolutos. Por outro lado, na medida em que adere às proposições discursivas da linguagem cinematográfica que se orientam para a instalação da continuidade narrativa, pauta-se na adoção da lógica concreta que impõe a homogeneização dos elementos significantes visuais e narrativos. Fechados em si mesmos, os sentidos produzidos pelos objetos visuais autônomos não se prestam ao arranjo compositivo da continuidade narrativa.

No processo de recuperação de sua importância para a cinematografia francesa da época (e consequente influência no cinema mundial), as abordagens de L'Inhumaine apresentam tratamento contraditório de seus aspectos visual e narrativo, sempre remetendo às declarações de L'Herbier de que a história era um pretexto para as experimentações visuais. Produzido no contexto de pesquisa das relações de correspondência entre as artes e da concepção do cinema como síntese de todas as manifestações artísticas, o filme utiliza-se de diferentes expedientes estilísticos, a fim de obter expressões visuais que enfatizem pontualmente aspectos psicológicos das personagens e dramáticos da narrativa. O sucesso das operações de ênfase visual dos constituintes narrativos, operadas separadamente com base nas relações de significação caso a caso, ao se articularem com o conjunto da narrativa apresentam uma competição de discursos, que finda por provocar rupturas da continuidade do universo diegético.

A despeito das declarações de seu diretor de que considerava o enredo de L'Inhumaine pouco importante, é na medida em que se aplica a utilização hiperbólica da visualidade a seu serviço que a narrativa desse filme fere as convenções do dispositivo cinematográfico de representação. No 
momento em que ocorrem as alternâncias de códigos visuais (como na passagem do exterior para o interior da Villa Lescot), estas atuam em sentido oposto à enunciação. Ao se revelarem assim, como operações arbitrárias, fazem cair por terra os pressupostos do acordo tácito que regem a relação expectador/filme na representação cinematográfica.

O estudo do cinema das vanguardas cinematográficas dos anos 1920, em especial a primeira vanguarda cinematográfica francesa, dadas suas características de utilização privilegiada dos aspectos visuais para a construção de sentido, apresenta-se como um campo fecundo para o estudo da especificidade dos códigos da direção de arte. Baseados em pesquisas teóricas acerca da especificidade do cinema, os cineastas desse grupo apontam para propostas estéticas que envolvem certo coeficiente de irrealismo, sendo alternativas ao modelo da narrativa realista, que se estabelece como hegemônico do cinema de ficção. Ao propor um tratamento privilegiado das possibilidades expressivas do aspecto visual e paralelamente estruturar a enunciação fílmica, com vias a apresentar um universo ficcional homogêneo, através de códigos calcados no modelo de representação que subordina a narrativa à restituição de uma suposta realidade, L' Inhumaine apresenta uma contradição interna em seu discurso. $\mathrm{O}$ exame dessa contradição evidenciou a autonomia expressiva dos códigos visuais aplicados no âmbito da direção de arte, nesse filme em particular e na linguagem cinematográfica em geral.

Enquanto representação visual do ideal de modernidade, ou como expressão visual passível de sobrepor seus elementos significantes à narrativa cinematográfica, a direção de arte demonstra-se enquanto um campo autônomo de significação de grande importância para a constituição da imagem cinematográfica. Nesse sentido podemos afirmar que no conjunto do discurso cinematográfico clássico narrativo, o uso das atribuições significativas da linguagem visual autônoma da direção de arte se dá de forma funcional, uma vez que seu uso se dá no interior de um sistema mais amplo de significação. Na medida em que se utiliza de seus recursos para a construção de um universo diegético naturalizado, de restituição de uma suposta realidade contínua e linear, o cinema clássico narrativo camufla a dimensão autônoma das significações visuais da direção de arte. Uma aproximação mais atenta de sua imagem, no entanto, revela que a forma como os seus elementos são empregados resulta de um complexo processo de criação de um espaço fictício, ao invés do aparente registro de um espaço dado.

Enquanto expressão ideológica o discurso cinematográfico apresenta as concepções a respeito das funções socioculturais que se pretendem para o dispositivo cinematográfico, por conseguinte, a naturalização dos significantes estéticos da direção de arte no conjunto desse discurso, se apresenta 
como consequência dessas concepções. Nesse sentido, pode-se afirmar que há tantas possibilidades para a utilização dos componentes expressivos desse campo, quantas são as formas possíveis de estruturação da imagem cinematográfica.

\section{Bibliografia}

ALBRECHT, Donald. Designing Dreams: Modern Architecture in the Movies. Santa Monica: Hennesey + Ingalls, 2000 .

ARGAN, Giulio Carlo. Arte Moderna. São Paulo: Companhia das Letras, 1992.

AUMONT, Jaques. A Imagem. $2^{a}$ edição. Campinas: Papirus, 1995.

AUMONT, Jacques; MARIE, Michel. Dicionário Teórico e Crítico de Cinema. Campinas: Papirus, 2006.

. A análise do filme. Lisboa: Texto \& Grafia, 2009.

AUMONT, Jaques et al. A Estética do Filme. $5^{\text {a }}$ edição. Campinas: Papirus, 2007.

BARTHES, Roland. A retórica da imagem. In: O óbvio e o obtuso. Rio de Janeiro: Nova Fronteira, 1990.

BAUDRILLARD, Jean. O sistema dos objetos. São Paulo: Perspectiva, 1973

BAUDRY, Jean-Louis. Cinema: efeitos ideológicos produzidos pelo aparelho de base. In: A Experiência do Cinema: antologia. Rio de Janeiro: Edições Graal: Embrafilme, 1983. Coleção Arte e Cultura. Vol 5

BENJAMIN, Walter. Magia e técnica, arte e política - (Obras escolhidas I). São Paulo: Brasiliense, 1996.

BERMAN, Marchall. Tudo o que é Sólido se Desmancha no Ar. São Paulo: Editora Schwarcz, 1986.

BERTHOMÉ, Jean-Pierre. Le Décor au Cinéma. Paris: Cahiers Du Cinema, 2003

BUTRUCE, Débora Lúcia Vieira. A Direção de Arte e a Imagem Cinematográfica: Sua inserção no processo de criação do cinema brasileiro dos anos 1990. Dissertação de mestrado, Niterói, UFF, 2005.

CABANNE, Pierre. Encyclopedie Art Déco. Paris: Somogy, 1986.

CHARNEY, Leo \& SCHWARTZ, Vanessa (Org). O Cinema e a invenção da vida moderna. São Paulo: Cosac \& Naify, 2004.

COSTA, Antonio. Compreender o Cinema. São Paulo: Globo, 2003

COSTA, Flávia Cesarino. O Primeiro Cinema. São Paulo: Scritta, 1995. 
DE MICHELLI, Mario. As Vanguardas Artísticas. São Paulo; Martins Fontes, 2004.

DONDIS, Donis A. Sintaxe da Linguagem Visual. São Paulo: Martins Fontes, 2007.

ETTEDGuI, Peter. Production Design \& Art Direction. Crans-Près-Céligny, London: Roto Vision, 1999.

GAINES, Jane. Costume and Narrative: How Dress Tells the Woman's Story. In: GAINES, Jane; Herzog, Charlotte (ed). Fabrications. Costume and the Female Body. New York: Routledge, 1990.

GUNNING, Tom. Cinema e História. Fotografias animadas, contos do esquecido futuro do cinema. In: XAVIER, Ismail (Org). O Cinema no Século. Rio de Janeiro: Imago, 1996.

HAGENER, Malte. Moving Forward, Looking Back. Amsterdam: Amsterdam University Press, 2007.

HAUSER, Arnold. Concepto de la ideologia em la historia del arte. In: Introduccion a la historia del arte. Coleccion Guadarrama de Critica e Ensaio, vol. 33. Madrid: Guadarrama, 1969.

KATZ, Steven D. Film directing shot by shot: visualising from concept to screen. Studio City, CA: Michel Wiese Productions, 1991.

LOBRUTTO, Vincent. The filmmaker's guide to production design. New York: Allworth Press, 2002.

MALLET-STEVENS, Robert. Le Décor au Cinéma. Paris: Seguier, 1996.

MARTINS, Fernanda A. C. Impressionismo Francês. In: MASCARELLO, Fernando (Org).

História do Cinema Mundial. Campinas: Papirus, 2006.

METZ, Christian. A Significação no Cinema. São Paulo: Perspectiva, 1972.

PAPIEAU, Isabelle. L’Art Déco. Une esthétique émancipatrice. Paris: L’ Harmattan, 2009.

POIRET, Paul. King of Fashion. The autobiography of Paul Poiret. Londres: V\&A Publishing, 2009.

RAMOS, Fernão. Cinema e Realidade. Alguns aspectos estruturais da imagem-câmera e sua particular intensidade. In: XAVIER, Ismail (Org). O Cinema no Século. Rio de Janeiro: Imago, 1996.

SADOUL, Georges. História do Cinema Mundial - Volume I. São Paulo, Martins, 1963.

TELES, Gilberto Mendonça. Vanguarda Européia e modernismo brasileiro. 10 ${ }^{\text {a }}$ Ed. Rio de Janeiro: Record, 1987.

VANOYE, Francis; GOLIOT-LÉTÉ, Anne-Marie. Ensaio sobre a análise fílmica. $6^{\text {a }}$ edição.

Campinas: Papirus, 2009. 
XAVIER, Ismail. O Discurso cinematográfico. Rio de Janeiro: Paz e Terra, 1977.

. Cinema e Teatro. A noção clássica de representação e a teoria do espetáculo, de Griffith a

Hitchcock. In: (Org). O Cinema no Século. Rio de Janeiro: Imago, 1996.

\section{Periódicos}

L' HERBIER, Marcel. L'Inhumaine et les Arts décoratifs. Comoedia, Paris, 24 jul.1925. Exemplar da coleção Hédy Sellami. Disponível em <http://www.eclairages.eu/L-inhumaine-et-les-Artsdecoratifs_a840.html >. Acesso em: 29 set. 2009.

F.F. “L’Inhumaine” reprend des couleurs - L'Express. Paris, 17 out.1986.

NASRALLAH Raja, L’ Autre Journal. Paris, 07 mai.1986.

SICLIER, Jacques. Manifeste art déco. Le Monde. Paris, 23 out. 1986.

\footnotetext{
${ }^{\mathrm{i}}$ Adjetivos retirados da cartela de apresentação da personagem. Excerto de DVD que apresenta a cópia restaurada em 1986 pelo C.N.C., produzida por ocasião do evento Le $2^{\circ}$ Printemps des Ciné Concerts Bordeaux. Time code 00:02:58. No original em francês: "riche, affranchie, inaccessible aux ambitions ordinaires".

ii Terminologia francesa muito utilizada por Robert Mallet-Stevens para designar seus projetos residenciais construídos fora das aglomerações urbanas. Será adotada também essa nomenclatura para a residência de Claire, que chamaremos Villa Lescot.

iii Utilizado aqui, na acepção de Rohmer, como realidade natural ou construída, com a qual o cineasta se confronta no momento das filmagens. COSTA, 2003, p. 230-231.
} 